\title{
Assessing Hospital Employees' Readiness for Change for a Workplace Wellness Program
}

\author{
Deborah Lynne Motley and Mike Prelip \\ University of California, Los Angeles
}

\begin{abstract}
The aims of this study were to measure attitudes of hospital employees towards health and healthy behaviors and provide exploratory research that will guide stakeholders in strategically planning a worksite wellness (WW) program at a Catholic hospital. Methods used included a cross-sectional study with census data from a population of employees in a hospital utilizing Prochaska's Stages of Change to assess their readiness. Participants $(\mathrm{N}=705)$ were also asked to identify 1$)$ meaningful WW incentives, 2) job stressors encountered and 3) if spirituality/religiosity played a role in their health. Using frequency and Chi-square distributions, this census survey revealed a readiness to engage in exercise, weight control and stress management. A higher engagement in positive health behaviors was seen in those who reported spirituality/religiosity, especially when involved in a spiritual/religious community. Major themes suggested that this hospital would benefit from WW incentives that target exercise, weight control and stress management and that allow employees to pursue these health goals in supportive relationships with each other. A unique holistic approach to worksite wellness, incorporating "body", "mind", and "spirit" is discussed and ultimately guided the interpretation and application of the survey data.
\end{abstract}

(C) 2011 Californian Journal of Health Promotion. All rights reserved.

Keywords: Workplace wellness/incentives, needs assessment, health survey, stages of change, health behaviors, religion/spirituality, faith-based organization.

\section{Introduction}

Workplace Wellness (WW) programs are employer health programs aimed to promote and protect employee health in the occupational setting. Research has shown favorable results when worksites offer programs that improve diet, increase exercise, promote weight loss, lead to smoking cessation, and promote the acquisition of stress-reduction techniques (Sparks, Faragher, \& Cooper, 2001). In addition to encouraging healthy employee habits, WW programs can affect psychological and spiritual health as well (Giacalone \& Jurkiewicz, 2003). WW programs not only provide competitive and personal benefits to employees but also help organizations to contain costs and increase productivity (Sara, Helen, \& Starley, 2008). WW programs show promise for businesses as they can control health care costs and health insurance premiums. More than 50 percent of corporate profits are now going towards health care costs, versus only 7 percent three decades ago (Powell, 2009). Furthermore, it is estimated that about 44 percent of the payroll expenses in the average business will go straight to paying the costs for employee benefits (US Chamber of Commerce [USCOC], 2007). Healthy people make productive employees. Companies that offer comprehensive WW programs have seen a $25-30 \%$ decrease in medical and absenteeism costs over a 3.5-year period (News Observer, 2008). The average return on investment for employers has been anywhere from 3 to 6 per dollar spent on employee wellness (US Department of Health and Human Services [DHHS], 2008).

DiClemente, the co-developer of the Transtheoretical Model of Behavior Change, 
urges program planners to address "multiple behaviors" and consider social influences and environmental factors that influence these behaviors (Werch, Ames, Moore, Thombs, \& Hart, 2009). Practitioners are to get to know the individuals in a population, "body", "mind", and "spirit", as this provides baseline data and acts as a first step in program evaluation.

\section{What is being done to support "body"?}

Many hospitals have taken advantage of worksite health promotion companies, who are eager to provide their services, rightly stating "when we take care of ourselves, we are better prepared to help others in our care" (Mercy Health Workforce Initiative, 2009). WW companies maintain that they can identify and address employee health risks before they result in costly claims. Some hospitals have adopted such programs including LoneStart's 'Caring for the Caregivers,' a hospital employee wellness initiative. LoneStart's program offers a weight loss challenge with other participating hospitals, which can be effective, can improve morale, (Lowe, Schellenberg, \& Shannon, 2003), and increase a hospital's credibility of a healthy culture able to care for its community. Weight loss competitions are usually are very popular with staff and increase their physical activity, but have not been shown to maintain lost weight when the competition is over (Stunkard, Cohen \& Felix, 1989).

Wellness interventions commonly offered to hospital staff are Health Risk Appraisals (HRAs) that help identify unhealthy behaviors (Green \& Kreuter, 2005, p.337) and online classes; external web-based tools that personalize education towards the recipient. However, from a program planning perspective, WW programs that are "designed and implemented in a way that fits the organizational culture tend to be more effective than those that do not" (Green \& Krueter, 2005; Harden, Peersman, Oliver, Mauthner, \& Oakley, 1999). Interventions tailored to match stages of behavioral readiness (Taylor et al., 2004) and involving staff more directly in decisions relative to wellness offerings (Campbell, 1993) can establish appropriate objectives and evaluation criteria for whatever programs are eventually adopted.

\section{What is being done to support "mind"?}

Health care workers are exposed to a number of stressors. Work overload, time pressures, long shifts, and for some, lack of role-clarity: these are not conducive to a healthy workplace environment. Lack of role-clarity, or a clear understanding of the requirements of one's role in handling infectious diseases and dealing with the very sick, can be especially burdensome (The National Institute for Occupational Safety and Health [NIOSH], 2008). Workers are stretched by the lack of proper or functioning equipment, lack of training on how to do their job, or lack of support from others (Spector \& Jex, 2008). Such stressors can lead to psychological, behavioral, or physical reactions, (Lowe et al., 2003). High stress jobs have been linked with psychological distress, pain, and reduced physical functioning among nurses (Bourbonnais, Comeau, \& Vezina, 1999). Further, long shifts and high job demands among many categories of employees have been shown to link stress to weight gain (Centers for Disease Control [CDC], 2009; DHHS, 2009).

Tackling job stress requires participatory approaches in re-organizing patient care and addressing the job constraints that are barriers to work flow (Hamelin, Brabant, Lavoie-Tremblay, Viens, \& Lefrancois, 2007). The National Institute for Occupational Safety and Health (NIOSH) advocates multidisciplinary rounds, which enable all disciplines caring for patients to come together and offer expertise in patient care. This creates a collaborative and supportive environment that in turn encourages healthy behaviors and reduces stress among health care workers (NIOSH, 2008). Also, measuring judgments employees make about the nature of their jobs and related work environment (Fields, 2002) have been used to address stressors in the workplace. This avoids the perceived paternalism of putting all the responsibility for health behavior change on the individual. For example, Canada's Workplace Health Strategies Bureau points out that high job stress impedes 
WW intentions if they fail to support the psychological health of their employees (Lowe, 2004).

\section{What is being done to support "spirit"?}

Health and wellness are positively correlated with both religious and spiritual involvement. An overarching theory explaining the interrelationships between religion/spirituality and health is called the "prevention model," which suggests that religion has both direct and indirect positive effects on health (Ellison \& Levin, 1998; Chatters, 2000; Fetzer Institute, 2003). Factors that link religion and health generally include practicing specific healthy lifestyle and coping behaviors; seeking help within social resources inherently provided within a spiritual/religious community; and possessing positive worldviews associated with better health (Chatters, 2000). These conceptual models linking religion and health can play a role in occupational stress and well-being.

Advocating spiritual wellness at work, a norm at Catholic organizations, may seem to some, an infringement on autonomy. However, Pelligrino asserts that health promotion, regardless of motivation, is a moral obligation as it contributes to not only to the well-being of an individual, but to the social organism as a whole (Pellegrino, 1984). Spiritual WW activities may include yoga or meditation (Giacalone et al., 2003). One WW program offers workshops to hospital employees to increase self-efficacy "within themselves, in their job roles, and in relationships with co-workers" (Emmons, Linnan, Shadel, Marcus \& Abrams, 1999). Their (unpublished) data reports improved employee and patient satisfaction.

Many tools help measure spiritual wellness (Fetzer Institute, 2003). For example, the Beliefs and Values scale was specifically designed to examine the role of spirituality in health-seeking behaviors (King, Jones, Barnes, Low, Walker, Wilkinson, Mason, Sutherland \& Tookman, 2006). Puchalski at George Washington Institute of Spirituality and Health has similarly developed a tool to assess whether a person's spirituality or religiosity affects their health (Puchalski \& Romer, 2000). This questionnaire by Puchalski and Romer (2010) examines the importance one places on faith and beliefs and if it influences self-care. It also addresses if these beliefs are practiced in the context of community (George Washington Institute, 2008). Measuring religion/spirituality in this way together with the Transtheoretical Model may contribute to WW literature and our understanding of what WW activities should eventually be offered (Wholey, Hatry, \& Newcomer, 2004; Watts, Donahue, Eddy, \& Wallace, 2001; McLeroy, Bibeau, Steckler, \& Glanz, 1988).

\section{Theoretical framework}

DiClemente and Prochaska's Transtheoretical Model was used to measure behavioral readiness (Prochaska, 1997). This model classifies individuals into several categories according to their readiness for change to adopt a healthy behavior: precontemplation (unaware, not intending to take action in the next six months); contemplation (intending to change in the next six months); preparation (intending to take action in the next month); action (actively modifying habits within the past six months); maintenance (sustaining new, healthier habits for more than 6 months) (Cancer Prevention Research Center, 2008). From a general health promotion perspective, if a modifiable risk factor emerges from an assessment of a population's motivational readiness, this should be the focus of future interventions. Literature supports phasing a campaign effort by focusing on those most ready for action (Kotler \& Lee, 2008). Furthermore, best practices show that focusing on a health priority that was defined by a group of workers will be have a higher participation rate (Linnan, Sorensen, Colditz, Klar, \& Emmons, 2001).

\section{The present study}

A cross-sectional design was used as a part of a needs assessment of hospital employees. Research questions that guided the survey design were as follows:

Body - The purpose of these research questions was to discover how engaged employees were in eight different health behaviors, including: 
(1) Which health promoting behavior(s) were employees ready to take action on?

(2) What was the most frequently requested WW incentives for those that are ready to take action in the eight health behaviors?

Mind - The purpose of these research questions was to explore how employees perceive their job and the stress that it can provoke:

(3) What was the level of self-reported stress for the different job categories?

(4) Was engagement in health promoting behaviors associated with self-reported job stress?

Spirit - The last research question was to evaluate if religion/spirituality is associated with employee health behaviors.

(5) Was engagement in health promoting behaviors associated with self-reported spirituality/religiosity?

\section{Methods}

\section{Participants}

The priority population consisted of 2309 employees categorized by California's Health and Human Services Agency's Office of Statewide Health Planning and Development (OSHPD) "natural classification" (Office of Statewide Health Planning and Development, 1991). These employees were largely female (about 77\% female, 23\% male), in their 40's with an employment tenure ranging from about 6-15.5 years. The majority of the study sample consisted of: Asian (15.4\%), American Indian/Alaska Native (0.6\%), African American (2.2\%), Hispanic/Latino (21.2\%), Non-Hispanic White (59.4\%) and Unknown/Not specified $(1.3 \%)$.

Although little was known about the staff's health, statistics about the county where $91 \%$ of all employees live (Butler, 2009) were available.
According to a needs assessment (OCHNA, 2005), $42 \%$ to $56 \%$ of Orange County adults were either overweight or obese. Additionally, $32.9 \%$ of these overweight/obese individuals were diagnosed with high blood pressure, $26.4 \%$ with high blood cholesterol, and $12.5 \%$ with diabetes. A 2007 California Health Interview Survey (CHIS) confirmed these findings, stating that $51.3 \%$ of adults in southern California counties were either overweight or obese (California Health Interview Survey [CHIS], 2008). Furthermore, the 2003 Behavioral Risk Factor Surveillance System (BRFSS), stated that more than half ( $54 \%$ of California's adults) did not meet recommended guidelines for physical activity (Morbidity and Mortality Weekly Report [MMWR], 2008).

In addition to these findings, unpublished reports derived from insurance providers showed that employee claims from hospitals were associated with preventable illnesses including heart and back conditions, injuries such as fractures, eating disorders and obesity, and "self care". Self-care conditions included headache, abdominal pain, upper respiratory infection, fever, and nausea. Common prescriptions filled were for depression, gastro-intestinal disorders, elevated cholesterol, diabetes, hypertension, and pain management.

\section{Setting}

The hospital was a 341-bed, acute care, full service facility in southern California that is part of a not-for-profit Catholic health care system. The hospital had a medical staff of more than 600 physicians, over 2,300 employees, and 1,235 volunteers. Areas of specialization included: trauma and 24-hour emergency care; maternity services; orthopedic and sports medicine services; chest pain center; vascular institute and stroke center; and an acute rehabilitation unit. Grounded in the Catholic Church's social teaching or beliefs regarding employer/employee relations, this hospital is committed to the health needs of the employee: "body, mind, and spirit."

\section{Measures}

A 28 question tool was designed to measure demographics, attitudes towards healthy 
behaviors and potential wellness offerings, job stress, and spirituality. Three introductory questions covered participant rights and identified eligible participants.

Demographic and employment questions included years worked at the hospital, primary type of work, age, gender and race. Stages of change questions addressed eight health promoting lifestyle practices and modifiable risk factors (Lam, Chan, Ho, \& Chan, 2004). One question determined the type of benefits that the participant would like to see offered to him/her. Three job stress questions were a modification of Spector's Organizational Constraints Scale (Spector \& Jex, 1998) Five spirituality questions were assessed to operationalize the religionhealth association and were adapted primarily from the work of Christina Puchalski (Puchalski \& Romer, 2000). Questionnaire specifications and a copy of the instrument can be obtained from the authors.

\section{Procedures}

The survey was conducted during the benefits enrollment period in November 2008. Eligible employees were able to use any computer with Internet access to select benefits and levels of coverage for the following year. During the regular process of selecting benefits, employees were invited to participate in a short, incentivized, 10-minute health questionnaire. The hospital's annual wellness fair also provided a paper version of the same questionnaire for employees who did not fill out the online questionnaire or who were not eligible for benefits enrollment. English and Spanish questionnaires/speakers were available, and respondents were given a $\$ 5.50$ meal ticket for use in the hospital cafeteria or coffee cart.

According to the demography of the study population likely to be involved, particular attention was paid to recruiting the Hispanic population, who typically do not participate in online surveys conducted at this hospital. Every effort was made to conduct the study in the participant's native language including translating written materials and/or instruments to Spanish and involving a Spanish interpreter at the wellness fair.
The questionnaire was anonymous and did not contain personal identifiers. Respondents were able to opt out at any time. An accessible participant information sheet outlined the purpose, procedure, potential risks and discomforts, possible benefits, compensation, confidentiality, the name and contact numbers of the investigators, and human subject rights of the survey. Those who proceeded to fill out the questionnaire were considered consenting participants, therefore, a separate consent was not deemed necessary by the IRB. Eligible participants were staff that had met all conditions of employment as defined by the hospital's employee handbook. Ineligible participants were identified through a screening process and were not included in the survey results.

\section{Analysis}

The Statistical Package for the Social Sciences, version 17.0, (Chicago, IL) was used for data analysis. In order to ascertain whether the sample was representative of the employee population, frequencies were obtained on sex, racial/ethnicity, and job categories for the eligible hospital staff and were compared to sample percentages using chi square analysis. For research questions one and two, descriptive statistics were conducted to determine the prevalence of health behaviors employees were ready to take action on and the popularity of WW incentives. For research question three, frequencies and percentages of job stress for each of the six OSHPD categories were calculated. For research question four, relationships between job stress and health behaviors were evaluated by using chi-square and independent samples t-tests, respectively. For research question five, chi-square tests and Pearson's correlation coefficients were used to explore associations between the spiritual questions and the health behaviors.

\section{Results}

Thirty-percent $(n=705)$ of the 2309 employees eligible to participate in the survey responded. Demographics of respondents were representative of the larger hospital population for Hispanic vs. non-Hispanic (American 
Indian/Alaska Native, African American/Black, White, Other and Not Specified) where $\chi^{2}$ $\mathrm{p}=0.266$, and for three of the six OSHPD categories (management and supervisory; technicians and specialists; EVS and NCS) where $\chi^{2} \mathrm{p}=.089$. (See Table 1) The sample included a greater proportion of women than the hospital population.

Table 1

Demographic Profile of Sample and Hospital Population

\begin{tabular}{|c|c|c|c|}
\hline Demographic & $\begin{array}{c}\text { Sample } \\
(n=705) \\
n(\%)\end{array}$ & $\begin{array}{c}\text { Population } \\
(N=2309) \\
N(\%)\end{array}$ & $\begin{array}{c}\text { Chi Square } \\
\text { Statistic } \\
\chi^{2}\end{array}$ \\
\hline $\begin{array}{l}\text { Gender }^{\mathrm{a}} \\
\text { Male } \\
\text { Female }\end{array}$ & $\begin{array}{l}144(21.1) \\
558(78.9)\end{array}$ & $\begin{array}{c}538(23.3) \\
1777(76.7)\end{array}$ & $\begin{array}{l}3.954 \\
\mathrm{p}<.05\end{array}$ \\
\hline $\begin{array}{l}\text { Ethnicity }^{\mathrm{a}} \\
\text { Hispanic } \\
\text { Non-Hispanic }\end{array}$ & $\begin{array}{l}154(21.8) \\
548(78.2)\end{array}$ & $\begin{array}{c}490(21.2) \\
1824(78.8)\end{array}$ & $\begin{array}{c}1.236 \\
\mathrm{p}=0.266\end{array}$ \\
\hline OSHPD Category $^{a}$ & & & \\
\hline $\begin{array}{l}\text { Management/Supervisory } \\
\text { Technicians/Specialists } \\
\text { Environment/Nutritional Care }\end{array}$ & $\begin{array}{c}85(12.1) \\
137(19.4) \\
56(7.9)\end{array}$ & $\begin{array}{l}232(10.0) \\
462(20.0) \\
174(7.5)\end{array}$ & $\begin{array}{c}4.83 \\
p=.089\end{array}$ \\
\hline $\begin{array}{l}\text { Other Administrative } \\
\text { Nursing } \\
\text { Aides/Orderlies }\end{array}$ & $\begin{array}{l}187(26.5) \\
196(27.8) \\
38(5.4)\end{array}$ & $\begin{array}{l}328(14.0) \\
766(33.3) \\
347(15.0)\end{array}$ & N/A \\
\hline
\end{tabular}

\section{Health Behaviors}

The results of the eight health behavior questions are presented in Figure 1. For analyses purposes the responses Never, Rarely, or Sometimes was collapsed into the category Not Active. And the response categories Most of the time and Always were collapsed into the category Active. Based on these Not Active and Active categories: $; 55 \%(n=382)$ of respondents stated they were not Active exercisers, $46 \%$ $(n=378)$ not reducing their stress, $44 \%(n=304)$ not getting enough sleep, $43 \% \quad(n=303)$ not eating as they should, and $43 \%(\mathrm{n}=300)$ not maintaining a healthy weight. Generally speaking, the sample seemed to be more actively engaged in taking their prescription medicine $(64 \%)$ and reducing their alcohol (82\%) and tobacco intake $(92 \%)$ than the other positive health behaviors.

\section{Stages of readiness}

Figure 2 displays staged responses into one of three groups, based on a simplified stages of change model used by Wendell Taylor and colleagues (Taylor et al., 2004); Not ready (precontemplation), Ready (contemplation or preparation), and Active (action or maintenance). Exercise, stress management, and weight control, are the three behaviors staged participants reported that they were "ready" to take action on or "active" in their attempts, while nutrition, sleep, prescription compliance, alcohol intake, and tobacco use followed. 


\section{Figure 1}

\section{Percentage of active vs. not-active participants for eight health-related behaviors}

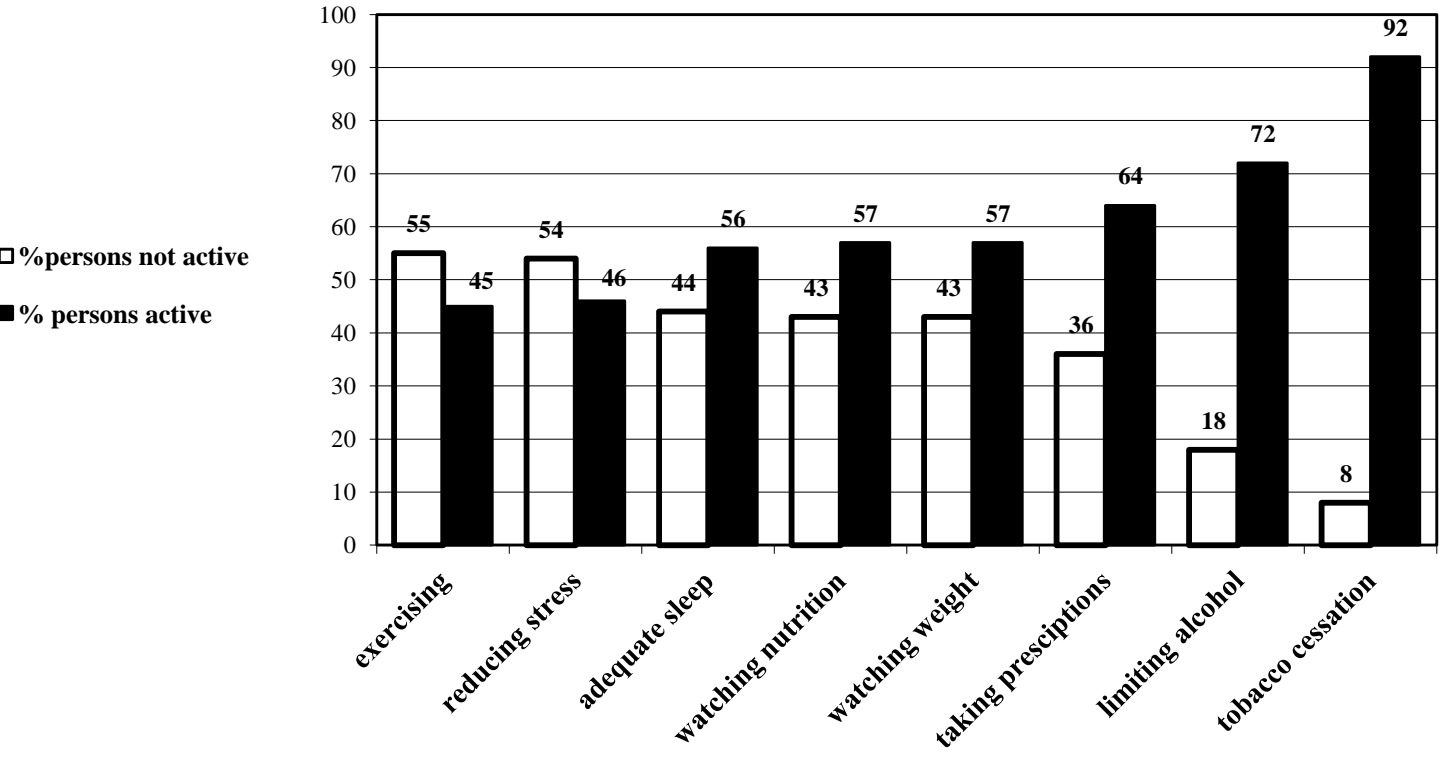

Behaviors

not active = "never", "rarely" or "sometimes" to a health behavioractive = "most of the time", "always" to a health behavior

Figure 2

Future behavior change by stages of readiness

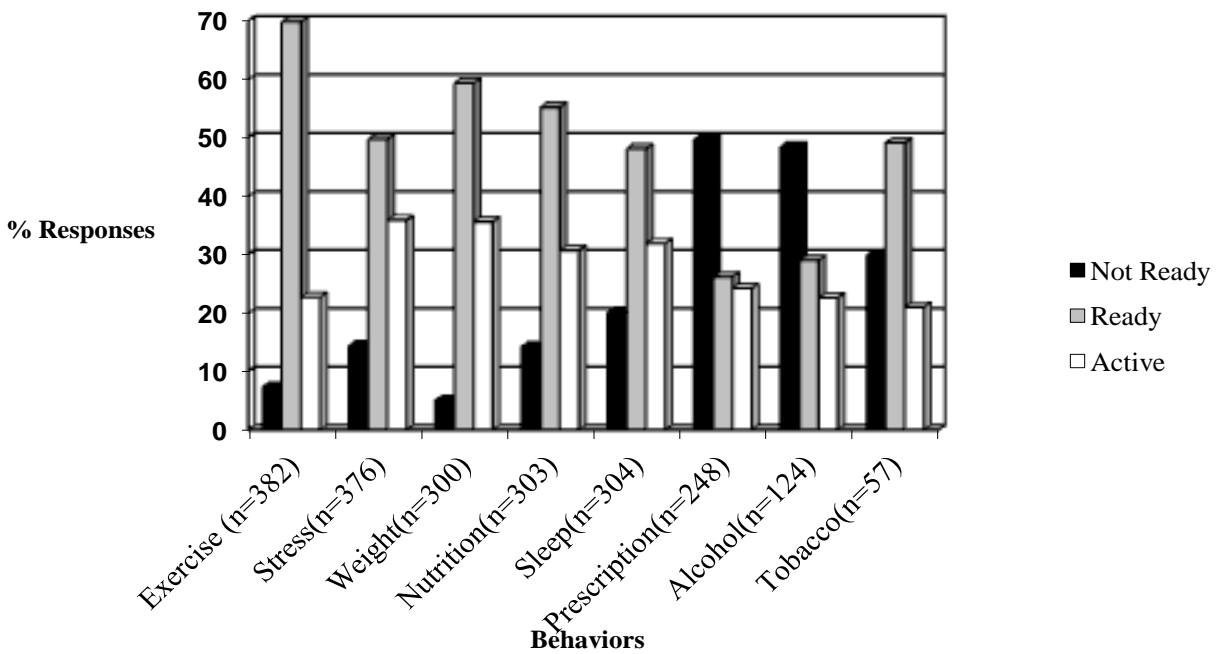

Not Ready = "Not intending to take action within the next 6 months; Ready = "Intending to take action within the next 6 months" and "Intending to take action within the next 30 days; Active = "Acting on it now, but for no more than 6 months and "Acting on it now and have been for more than 6 months" 


\section{Interest in WW incentives among those who are ready to take action in the eight health behaviors}

The three most requested incentives for those who were staged "ready" or "active" are: 1) onsite gym $(n=214), 2)$ personal coach $(n=177)$, and 3) discounts in exchange for exercise $(n=153)$. The rest of the requests, in decreasing in popularity, were: health-risk appraisals $(n=144)$, discounts for weight loss $(n=122)$, onsite classes $(n=118)$ health fairs $(n=103)$, walking teams $(n=102)$, online programs $(n=97)$, competitions $(\mathrm{n}=71)$, and discounts for smoking cessation $(n=40)$.

\section{Level of self-reported stress for different job categories}

While most job categories reported moderate job stress, as much as $40 \% \quad(n=37)$ of the Management/Supervisory respondents and $40 \%$ $(n=15)$ of the Aides/Orderlies expressed "severe" to "extreme" stress. As to the source of stress, $57.6 \%(n=406)$ cited the nature of their job and its responsibilities, $45.1 \%(n=318)$ the volume of work, and $19.9 \% \quad(n=140)$ relationships with co-workers.

\section{Relationship between job stress and health behaviors}

When conducting a comparison between the mean values of self-reported stress and the level of engagement ("active vs. "not active") in each of the behaviors, there were no significant differences by either chi-square or independent samples t-test results. This suggests that there were no associations between how engaged or "active" people were in the eight different health behaviors and self-reported job stress. For example, people who were "active" exercisers by previous definition did not self-report increased (or decreased) amounts of stress than non-exercisers (i.e. exercisers and nonexercisers are equally stressed).

\section{Perceived relationships between spirituality/religiosity and health behaviors} There were no associations between selfreported spirituality or religiosity and engagement in each of the behaviors. However, upon further analysis, it was found by a $\chi^{2}$ comparison that those who reported that they were spiritual/religious and in a supportive community $\quad(n=363)$ reported a higher engagement in all of the eight health behaviors compared to those who claimed to be spiritual/religious and not in a supportive community $(\mathrm{n}=222)$. This was statistically significant for exercise $\left(\chi^{2} \mathrm{p}=.036\right)$, nutrition $\left(\chi^{2}\right.$ $\mathrm{p}=.001)$, and maintaining a healthy weight $\left(\chi^{2}\right.$ $\mathrm{p}=.045)$. Figure 3 illustrates these findings.

\section{Other findings}

A significantly higher proportion $(65.8 \%$, $\mathrm{n}=264$ ) of those reporting to be spiritual/religious and in a supportive community felt there were "more positive than negative aspects" about their job and the work environment when compared with the spiritual/religious and not in supportive community. Conversely, those claiming to be spiritual/religious and not in a supportive community answered "more positive than negative aspects" only $34.2 \%$ of the time $(\mathrm{n}=137)$, where $\chi^{2} \mathrm{p}=.017$.

\section{Discussion}

Demographics of respondents are representative of the larger population as a whole for gender, race, and most OHSPD categories. Exercise, stress, and weight control were repeatedly expressed and perceived themes. Fifty five percent stated they are not exercising as they should (compared to a national average of 68\%), and $43 \%$ stated that they are not maintaining a healthy weight, which is similar to a national average of $41 \%$ (Saad, 2009). This corroborates 
Figure 3

\section{Spirituality/religiosity \& supportive community by type of behavior}
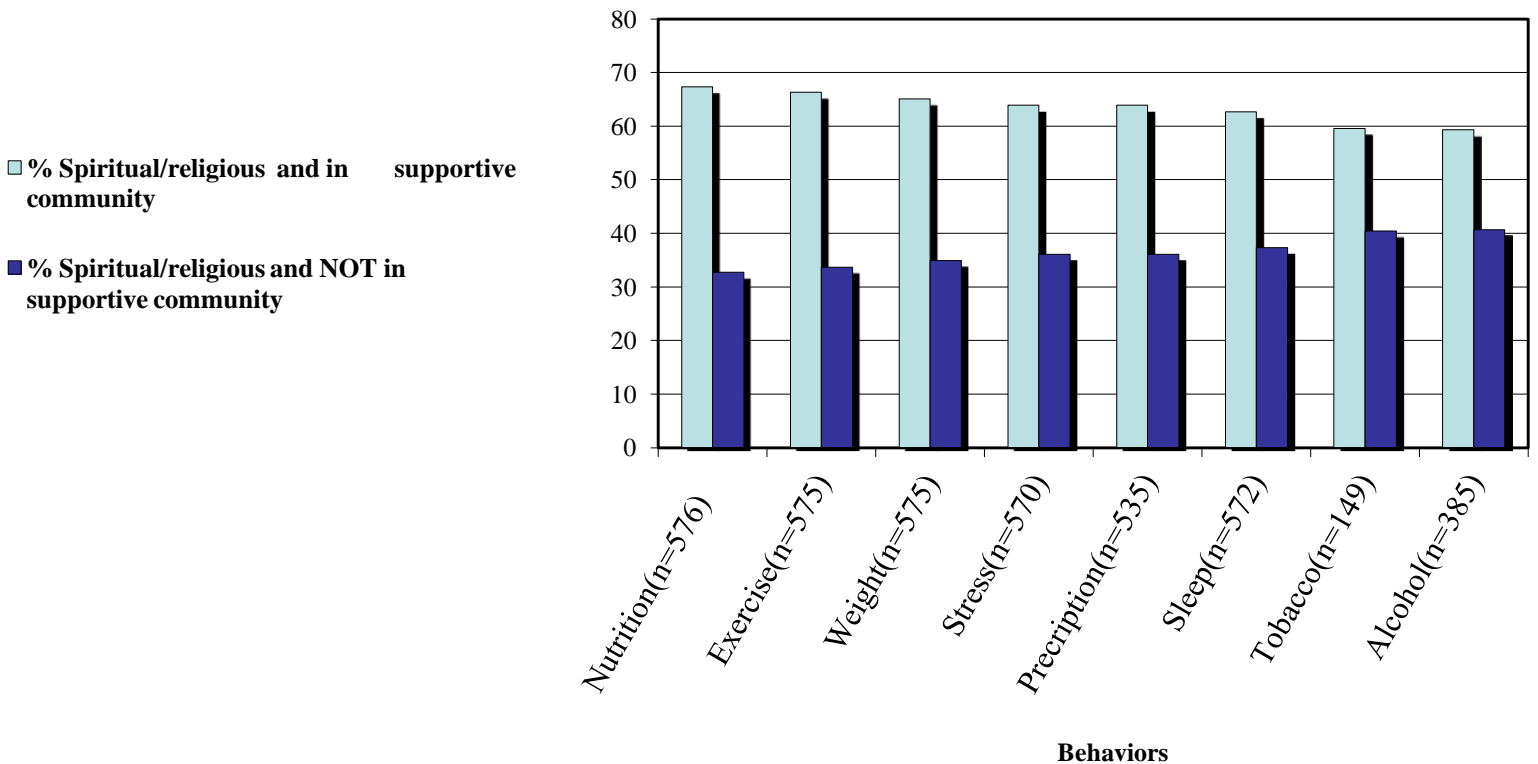

population's prescription and medical claims, exercise, stress and weight control are necessary interventions that will complement the treatment of the preventable illnesses accordingly.

While the original intent of this study was to focus on needs assessment for worksite wellness programming, unique to this study is also a holistic, "body, mind, and spirit" approach. Our findings underscore the influence of religion/spirituality on health. Within a supportive context, a "spiritual" connection may encourage compliance towards healthy behaviors and contribute towards a positive outlook. This is particularly relevant in a religious-based health care setting. Wellness activities to take care of oneself are in alignment with many religions and this framework can provide a potential motivation for employees not exhibiting healthy behaviors. Similarly, other institutions would do well to not only test employee attitudes towards health behaviors and their readiness to change but to include a novel, spiritual approach/component as well.

\section{Implications}

Employees infrequently answered with precontemplation (or "not intending to take action within the next 6 months"). This suggests that the employees are very aware of the importance of healthy behaviors such as exercise. Solely focusing on health statistics or giving them more knowledge may not be an appropriate strategy given the readiness of this population (Kotler \& Lee, 2008). Instead, offering them the time, place, opportunity and motivation to engage in healthy behaviors is preferred. In fact, provision of physical activities during work hours has recently shown to be one of the most popular incentives offered to Blue Cross/Blue Shield WW participants in North Carolina (News Observer, 2008). Therefore, budgeting for the improvement and promotion of the existing onsite gym is recommended.

Recruiting employees to help with WW teams, competitions, or challenges could strengthen the social health of the hospital's environment (Stunkard, Cohen \& Felix, 1989) and build upon 
the religious community of employees. Volunteers could target the recurring behavioral themes of the survey, which could reduce the expressed/perceived stress of getting along with their co-workers. Accountability is formed, connections are enhanced, and morale improved with participation in team-building activities. Team building activities would also support another finding from the survey - that spirituality/religiosity is not enough on its own to motivate healthy behaviors. If exercise, eating well, and achieving a healthy weight are desired, it is best to pursue this in relationship with Orange County and California data as reviewed. Therefore, WW program activities and incentives should be designed and conducted in community, not in isolation. For example, a health risk appraisal is not recommended unless people with similar health risks are grouped together to work on their risks. Similarly, online classes are not recommend for this population, again because these are often done in isolation, and was not a popular incentive, especially for the Hispanic respondents.

Finally, because the "spiritual/religious" in supportive community have a significantly more positive perspective about their job as a whole, it is recommend that focus groups form to discuss WW offerings that might help the employee to perceive that they do, in fact, belong to a spiritual/religious community that is of support to them - their own organization. These focus groups, for example, can explore the types of services and referrals provided by the (heavily utilized) Employee Assistance Program and compare this to the internal mechanisms in place that attempt to meet the practical and emotional needs of employees in crisis.

This study once again demonstrates the need to clearly understand a population prior to the commencement of program development. It is easy to assume that the population of interest is similar to others but this is often not the case. By conducting a survey of population members, program planners are able to not only learn about the specific population's characteristics but also build trust and buy-in by demonstrating the aim of developing WW interventions specific to the organization. The worksite is an ideal location to develop and deliver wellness activities as most Americans spend the major part of their waking hours at work. Also, with little argument, the American population is in dire need of improving wellness promoting behaviors. Americans would benefit from having the opportunity to participate in wellness activities throughout their lives, including their communities, schools, and worksite. Health care delivery organizations, especially sick-care delivery systems, should be concerned with wellness.

\section{Limitations}

Study results may only be generalizable to this hospital, as it is unique. However, hospitals with similar mission statements, gender, ethnic/racial, average age, and OSHPD categories may find the survey procedures and/or results useful in developing their own WW programs. Generally speaking, the process of conducting this study is appropriate for other settings and could be considered a best practice for worksite wellness needs assessment. The individual, formulated survey questions may not be sensitive enough to measure all the facets of concepts related to health behaviors. Finally, self-reported health behaviors can be biased, in which participants may not accurately disclose negative behaviors.

\section{Conclusion}

In summary, there is preeminent value in surveying employees first. Major themes and key findings of this census survey suggest that this hospital population would benefit from WW incentives that embody the organizations' missions and policies to holistically support their employees. Specifically, it is recommended to tailor a WW program that utilizes or expands upon and promotes existing resources from within: multi-disciplinary teams; willing volunteers; co-workers with similar values, health intentions, or interests; and an existing wellness gym. External worksite promotions such as Health Risk Appraisals, online classes or mere demonstrations or displays are not recommended as they might tell people what they all ready know or not provide the accountability they need. Instead, the population this hospital has indicated their needs loud and clear - not only the intention to improve their 
health but that of needing each other to do so. It is recommended that appropriate employee councils form focus groups to discuss the results of this study, develop a WW committee, and strategically plan a formal WW program the targets these expressed and perceived needs for the population as a whole, "body, mind, and spirit." Since the completion of the study, this hospital has conducted several wellness focus groups and is getting ready to launch a wellness program that will use social media to allow employees to connect and challenge each other in their fitness and weight loss goals.

\section{References}

Bourbonnais, R., Comeau, M. Vezina, M. (1999). Job strain and evolution of mental health among nurses. Journal of Occupational Health Psychology, 4, 95-105.

Centre for addiction and Mental Health (CAMH). Evaluate your drinking. Available at http://www.camh.net/. Accessed February 12, 2009.

Chatters, L. M. (2000). Religion and health: public health research and practice. Annual Review of Public Health, 21(1), 335-367.

Donaldson, S. I., Sussman, S., Dent, C. W., Severson, H. H., \& Stoddard, J. L. (1999). Health behavior, quality of work life, and organizational effectiveness in the lumber industry. Health Education \& Behavior, 26(4), 579-591.

Ellison, C.G. \& Levin, J.S. (1998). The religion-health connection: evidence, theory, and future directions. Health Education \& Behavior, 25(6), 700-720.

Emmons, K.M., Linnan, L., Shadel, W.G., Marcus, B. \& Abrams, D. (1999). The working healthy project: A worksite health-promotion trial targeting physical activity, diet, and smoking. Journal of Occupational and Environmental Medicine, 41(7), 545-555.

Fetzer Institute. (2003). National institute on aging working group: multidimensional measurement of religiousness, spirituality for use in health research. A report of a national working group. Kalamazoo, MI: Fetzer Institute

Fields, D.L. (2002). Taking the measure of work: A guide to validated scales for organizational research and diagnosis. Thousand Oaks, CA: Sage Publications.

Green, L. W., \& Kreutner, M. W. (2005). Health program planning. New York: McGraw Hill.

George Washington Institute for Spirituality and Health. FICA-Taking a spiritual history. Available at www.gwish.org/id69.htm. Accessed July 20, 2008.

Hamelin Brabant, L., Lavoie-Tremblay, M., Viens, C., \& Lefrancois, L. (2007). Engaging health care workers in improving their work environment. Journal of Nursing Management, 15(3), 313-320.

Harden, A., Peersman, G., Oliver, S., Mauthner, M., \& Oakley, A. (1999). A systematic review of the effectiveness of health promotion interventions in the workplace. Occupational Medicine, 49(8), 540-548.

King, M., Jones, L., Barnes, K., Low, J., Walker, C., Wilkinson, S., Mason, C., Sutherland, J., Tookman, A. (2006). Measuring spiritual belief: development and standardization of a Beliefs and Values Scale. Psychological Medicine, 36, 417-425.

Kolodinsky, R.W., Giacalone, R.A., Jurkiewicz, C.L. (2008). Workplace values and outcomes: exploring personal, organizational, and interactive workplace spirituality. Journal of Business Ethics. 81, 465-480.

Lam, T-H., Chan, B., Ho, S.-Y., \& Chan, W.-M. (2004). Stage of change for general health promotion action and health-related lifestyle practices in Chinese adults. Preventive Medicine, 38(3), 302308.

Linnan, L. A., Sorensen, G., Colditz, G., Klar, N., \& Emmons, K. M. (2001). Using theory to understand the multiple determinants of low participation in worksite health promotion programs. Health Education \& Behavior, 28(5), 591-607. 
Lowe, G. S. (2004). Healthy Workplace Strategies: Creating Change and Achieving Results: Workplace Health Strategies Bureau. Available at: http://www.grahamlowe.ca Accessed January 31, 2008.

McLeroy, K. R., Bibeau, D., Steckler, A., \& Glanz, K. (1988). An Ecological Perspective on health promotion programs. Health Education \& Behavior, 15(4), 351-377.

Office of Statewide Health Planning and Development. Accounting and reporting manual for California hospitals. § 2440.1, April 1991.

Pellegrino, E. D. (1984). Autonomy and coercion in disease prevention and health promotion. Theoretical Medicine, 5, 83-91.

Puchalski, C. Romer, A.L. (2000). Taking a spiritual history allows clinicians to understand patients more fully. Journal of Palliative Medicine, 3(1), 129-137.

Sara, B. M., Helen, A. H., \& Starley, B. S. (2008). Trends in employer-sponsored health insurance coverage for tobacco-dependence treatments. American Journal of Preventive Medicine, 35(4), 321-326.

Spector PE, Jex SM. Development of four self-report measures of job stressors and strain: Interpersonal Conflict at Work Scale, Organizational Constraints Scale, Quantitative Workload Inventory, and Physical Symptoms Inventory. Journal of Occupational Health Psychology. 1998; 3:356-367.

Taylor, W., Hepworth, J., Lees, E., Cassells, A., Gousse, Y., Sweeney, M. M., et al. (2004). Readiness to change physical activity and dietary practices and willingness to consult healthcare providers. Health Research Policy and Systems, 2(1), 2.

Watts, G. F., Donahue, R. E., Eddy, J. M., \& Wallace, E. V. (Summer 2001). Use of an ecological approach to worksite health promotion. American Journal of Health Studies Available at: http://findarticles.com/p/articles/mi m0CTG/is 3 17/ai 90301871/pg 1. Accessed January 31, 2008.

Werch, C. E., Ames, S., Moore, M. J., Thombs, D., \& Hart, A. (2009). Health behavior insights--The transtheoretical stages of change model: Carlo C. DiClemente, PhD. Health Promotion Practice, $10(1), 41-48$.

Wholey, J., Hatry, H., \& Newcomer, K. (2004). Chapter 1: Using logic models. In Handbook of Practical Program Evaluation.

$\underline{\text { Author Information }}$

Deborah Lynne Motley MPH RD CNSC*

UCLA School of Public Health

22926 Avenida Valverde

Laguna Hills, CA 92653

Email: dmatoss@cox.net

Telephone: (949) 365-2160

Fax: (949) 365- 2434

Mike Prelip MPH DPA CHES

Professor

Director, MPH Health Professionals

Department of Community Health Sciences

UCLA School of Public Health

* corresponding author 